\title{
CARACTERÍSTICAS AGRONÔMICAS, PRODUTIVIDADE E QUALIDADE FISIOLÓGICA DA SOJA "SAFRINHA" SOB SEMEADURA DIRETA, EM FUNÇÃO DA COBERTURA VEGETAL E DA CALAGEM SUPERFICIAL ${ }^{1}$
}

\author{
EDUARDO DO VALLE LIMA², CARLOS ALEXANDRE COSTA CRUSCIOL ${ }^{3 *}$, CLÁUDIO CAVARIANI3; \\ JOÃO NAKAGAWA ${ }^{3^{*}}$
}

\begin{abstract}
RESUMO - A produtividade da soja, no sistema de semeadura direta (SSD), pode ser influenciada pelo tipo de cobertura vegetal que antecede, bem como pela calagem superficial. Todavia, os efeitos dessa técnica sobre os componentes da produção e sobre a qualidade fisiológica das sementes têm sido pouco estudados, principalmente para a soja "safrinha" sob SPD. Assim, objetivou-se avaliar algumas características agronômicas, os componentes da produção, a produtividade e a qualidade fisiológica da semente da soja cultivada na "safrinha", em função de diferentes coberturas vegetais, com e sem calagem superficial, sob SSD. O experimento foi conduzido no ano de 1999/00, na Fazenda Experimental Lageado, FCA/UNESP/Botucatu-SP. O delineamento experimental foi o de blocos casualizados em parcela subdividida, com 4 repetições. As parcelas de $6 \mathrm{~m} \times 10 \mathrm{~m}$, foram constituídas de sorgo de Guiné vermelho e branco (Sorghum bicolor), milheto (Pennisetum americanum), painço (Panicum dichotomiflorum), vegetação espontânea e sem vegetação. Aos 53 dias após a emergência, as coberturas vegetais foram dessecadas e acamadas, seguindo-se a aplicação superficial de 3,1 tha-1 de calcário na metade das parcelas, visando à elevação da $\mathrm{V} \%=70 \%$. Após 2 semanas, realizou-se a semeadura da soja, cv. IAC-19, em "safrinha". Determinou-se o estande final, a altura de inserção da primeira vagem, a altura de planta, o número total de vagens e vagens chochas por planta, o número de sementes por vagem total, a massa de 100 sementes e a produtividade. Com relação à qualidade fisiológica das sementes determinou-se a germinação e o vigor, por meio dos testes de envelhecimento artificial, germinação a temperatura subótima, M.S. de plântula e condutividade elétrica. Na implantação do SSD, a cobertura vegetal e a calagem superficial não afetam as características agronômicas, os componentes da produção, a produtividade de sementes e a qualidade fisiológica das sementes de soja cultivadas em "safrinha", com exceção da condutividade elétrica.
\end{abstract}

Termos para indexação: Glycine max, componentes da produção, planta de cobertura, semente.

\section{AGRONOMIC TRAITS, YIELD AND PHYSIOLOGICAL QUALITY OF "SAFRINHA" (OFF-SEASON) SOYBEAN UNDER NO TILL AS A FUNCTION OF PLANT COVER AND SURFACE LIMING}

\begin{abstract}
Soybean productivity under the no till system (NTS) can be influenced by the preceding type of plant cover and surface liming. However, the effects of this technique on yield components and the seed physiological quality have been little studied, especially in ("safrinha") off-season
\end{abstract}

\footnotetext{
${ }^{1}$ Submetido em 11/121/2007. Aceito para publicação em 04/05/2008. Parte da Dissertação de Mestrado do primeiro autor apresentada à Faculdade de Ciências Agronômicas da Universidade Estadual Paulista - FCA/UNESP.

${ }^{2}$ Prof. Adjunto da Universidade Federal Rural da Amazônia - UFRA, Unidade Descentralizada de Parauapebas - UDP (UFRA/Carajás), Quadra
}

Especial, s/nº, CEP: 68515-000, Parauapebas - PA. eduardo.valle lima@ yahoo.com.br

${ }^{3}$ Prof. Adjunto do Departamento de Produção Vegetal, Faculdade de Ciências Agronômicas da Universidade Estadual Paulista/UNESP. CP: 237, CEP: 18603-970, Botucatu (SP). *Bolsista CNPq. 
soybean under NTS. Therefore, this study aimed to evaluate some agronomic traits, yield components, productivity, and physiological quality of soybean grown during the off-season ("safrinha"), as a function of different cover plants, with or without surface liming, under NTS. The experiment was conducted during the 1999/00 cropping season on the Lageado Experimental Farm, FCA/UNESP/ Botucatu-SP, Brazil. The experimental design was organized as randomized blocks in split-plots, with 4 replications. The $6 \mathrm{~m} \times 10 \mathrm{~m}$ plots consisted of broomcorn (Sorghum bicolor), millet (Pennisetum americanum), fall panicum (Panicum dichotomiflorum), spontaneous vegetation, and no vegetation. At 53 days after emergence the cover plants were desiccated and lodged, and a surface application of 3.1 t.ha-1 lime was made in half of the plots, in order to increase V\% to 70. Soybean (cv. IAC-19) was sown two weeks later, during the off-season ("safrinha"). Determinations were made for the final stand, first pod height, plant height, total number of pods and blank pods per plant, total number of seeds per pod, 100-seed weight and yield. As to seed physiological quality, determinations were made for germination, artificial aging, germination at $18^{\circ}$ C, plantlet D.M., and electric conductivity. During NTS implementation, plant cover type and surface liming did not affect the agronomic traits studied, yield components, seed productivity, and physiological quality of soybean seeds grown in the offseason ("safrinha") system, except for electric conductivity.

Index terms: Glycine max, yield components, cover plant, seed.

\section{INTRODUÇÃO}

É necessária à seleção de cobertura vegetal para compor um programa de rotação e sucessão de culturas, com a finalidade de proteção superficial do solo, formação de "palhada", bem como reciclagem de nutrientes, com impacto direto nos atributos químicos do solo e na resposta da cultura subseqüente. Para o sistema de semeadura direta (SSD), deve-se optar por espécies de gramíneas com elevada capacidade de produção de massa seca (M.S.), capazes de formarem uma proteção mais estável na superfície. O milheto tem se destacado e vem se constituído como uma das melhores opções de cobertura vegetal para o SSD, principalmente quando antecede ao cultivo da soja. Cordeiro e Souza (1999) constataram que, além da elevada produção de M.S., a cobertura vegetal morta do milheto influenciou positivamente algumas características agronômicas da cultura de soja e, em especial, a produtividade, enquanto que o tratamento com vegetação espontânea não foi eficiente na melhoria de nenhuma variável. Da mesma forma, Delavale et al. (2000), na implantação do SSD, verificaram incremento significativo na altura de plantas e na produtividade de soja, em função do resíduo de milheto.

Quanto à resposta da soja à calagem, a mesma é bastante conhecida quando se trata de cultivo convencional (Rossetto et al., 1994), sendo o corretivo devidamente incorporado ao solo. No sistema convencional de cultivo ou na implantação do SSD, a correção da acidez pressupõe a incorporação do calcário ao solo com aração e gradagens, para proporcionar o máximo contato entre as partículas do corretivo aos colóides do solo. Todavia, a maioria dos produtores que se encontram realizando semeadura direta, em sistemas já estabelecidos, não mais deseja utilizá-la, para não destruir as vantagens químicas, biológicas e físicas que foram ganhas durante os anos de adoção desse cultivo conservacionista. As evidências quanto à ação benéfica da calagem superficial atuando nas primeiras camadas abaixo da superfície do solo, em SSD já estabelecidos (mais de 4 anos), são hoje incontestáveis (Caires et al., 1999; Caires et al., 2000a). Estudos como os de Oliveira e Pavan (1996) e Sá (1999), demonstram a viabilidade dessa prática sobre a produção acumulada de grãos de soja em um sistema de rotação.

Atualmente, vem existindo interesse na busca de formas alternativas para implantação de culturas no SSD, em áreas nunca antes utilizadas com esse sistema de cultivo, sem a necessidade de promover o revolvimento inicial do solo por meio de preparo convencional, realizando-se a calagem superficial desde o estabelecimento (Caires et al., 2000b). As vantagens desse procedimento estariam relacionadas à manutenção das características químicas e estruturais do solo, ao maior controle da erosão e à economia com as operações de incorporação de calcário e preparo do solo (Caires et al., 2000b).

Recentemente, a eficiência da calagem superficial sobre 
a correção da acidez de subsuperfície, em SSD, tem sido associada à permanência dos resíduos vegetais na superfície e à ausência de revolvimento do solo, que reduz a taxa de decomposição dos ácidos orgânicos de baixo peso molecular, responsáveis por complexarem o $\mathrm{Ca}^{2+}$ e o $\mathrm{Mg}^{2+}$ do solo na camada superficial, que em função da carga nula ou negativa adquirida, são lixiviados para a subsuperfície onde deslocam o $\mathrm{Al}^{3+}$, formando complexos estáveis, liberando o $\mathrm{Ca}$ e o $\mathrm{Mg}$ e diminuindo a acidez trocável (Miyazawa et al., 1996).

Um outro aspecto de interesse a ser observado é a resposta da soja em "safrinha", num SSD recém implantado, pois o cultivo tecnicamente viável dessa cultura, no período de outono-inverno, possibilitaria uma alternativa ao milho "safrinha", funcionando como uma nova opção de fonte de renda. Neste contexto, não deve ser esquecida a relação existente entre o SSD e o cultivo em "safrinha", onde o primeiro possibilita a imediata semeadura, diminuindo os riscos climáticos do período, e o segundo proporciona a produção de fitomassa para a manutenção de um sistema de cultivo conservacionista.

A "safrinha" é o cultivo de "sequeiro", estabelecido após a cultura de verão na região centro-sul brasileira, destacando-se os estados do PR e de SP. No estado de SP, para a soja, uma das principais vantagens do cultivo em "safrinha" seria a coincidência da maturação e colheita com períodos climáticos mais favoráveis à obtenção de sementes de soja de melhor qualidade fisiológica e sanitária (Medina, 1994). Contudo, a época de semeadura é a variável que produz o maior impacto sobre a produção da cultura da soja, evidenciando uma atividade que pode ser de alto risco para o produtor. Em Botucatu-SP, Nakagawa et al. (1983) atribuíram a redução na produção de sementes de soja, a medida em que se atrasava a semeadura de meados de outubro ao início de janeiro, principalmente aos efeitos do fotoperíodo associado à ação de baixas temperaturas e à falta de umidade no solo. $\mathrm{O}$ estresse hídrico no início do período de formação de vagens, ou seja, estádio R3 (Fehr et al., 1971), causa maior redução no número de vagens e, conseqüentemente, no número de grãos (Rassini e Lin, 1981).

Mais recentemente, no município de Guaíra, ao norte do estado de SP, onde as temperaturas são mais elevadas no inverno, com a utilização de cultivares indiferentes ao fotoperíodo e, principalmente, em função da liberação da multiplicação de sementes de soja transgênica Roundup Read, tem sido utilizado esse sistema de cultivo em "safrinha", sob áreas irrigadas, para a multiplicação de sementes. Contudo, esse cultivo na entressafra pode promover uma continuidade do inóculo da ferrugem asiática durante todo ano. Como conseqüência, há relatos da ocorrência de ferrugem em soja no estádio vegetativo em áreas de Guaíra - SP, que se constitui na situação mais crítica para controle, havendo a necessidade de um número excessivo de aplicação de fungicida.

Neste sentido, em São Paulo, a partir do ano agrícola de 2007/2008 vem havendo uma adesão ao "vazio sanitário", sendo uma iniciativa dos próprios produtores rurais de Guaíra, aprovado pela Câmara Técnica da Soja (Embrapa, 2008). O "vazio sanitário" nada mais é do que uma medida de manejo, que no final da safra de 2004/2005 iniciou como uma Recomendação Técnica Conjunta do Ministério da Agricultura Pecuária e Abastecimento, sendo paulatinamente transformada em Instrução Normativa para cada estado produtor de soja, onde regulamenta-se um período de 90 dias sem soja, durante a entressafra, tanto a semeada quanto as plantas voluntárias (Embrapa, 2008).

Entretanto, o "vazio sanitário" não tem como objetivo resolver o problema da ferrugem, sendo essa medida, apenas uma estratégia que visa reduzir o inóculo nos primeiros plantios, diminuindo assim a possibilidade de incidência da doença no período vegetativo e reduzindo o número de aplicações. Portanto, trabalhos que estudem a viabilidade da condução da cultura da soja em "safrinha" não deixaram de apresentar importância prática, uma vez que, faltam resultados de pesquisa comprovando a influência do inóculo produzido na entressafra, além de que atualmente a única forma de evitar reduções de produtividade na presença da ferrugem é por meio da realização do controle químico.

O presente trabalho foi realizado com o objetivo de avaliar algumas características agronômicas, os componentes da produção, a produtividade e a qualidade fisiológica da soja cultivada na "safrinha", em função de diferentes coberturas vegetais, com e sem calagem superficial, na implantação do SSD.

\section{MATERIAL E MÉTODOS}

O trabalho foi desenvolvido em 1999/2000, na Fazenda Experimental Lageado, da FCA/UNESP-Botucatu-SP, a latitude $22^{\circ} 51^{\prime} \mathrm{S}$, longitude $48^{\circ} 26^{\prime} \mathrm{W}$ e altitude de $740 \mathrm{~m}$. $\mathrm{O}$ solo da área experimental é classificado como Nitossolo Vermelho típico (Embrapa, 2006), cujos atributos químicos antes da instalação do experimento, na camada arável $(0 \mathrm{a}$ 20cm), foram: $\mathrm{pH}\left(\mathrm{CaCl}_{2}\right), 4,8$; M.O., 23g.dm ${ }^{-3}$; P (resina), $19 \mathrm{mg} \cdot \mathrm{dm}^{-3} ; \mathrm{H}+\mathrm{Al}, 55 \mathrm{mmol}_{\mathrm{c}} \cdot \mathrm{dm}^{-3} ; \mathrm{K}, \mathrm{Ca}$ e Mg trocáveis, 1,8 ; $19 \mathrm{e} 13 \mathrm{mmol}_{\mathrm{c}} \cdot \mathrm{dm}^{-3}$, respectivamente; CTC, $89 \mathrm{e} \mathrm{V \% ,} 38$ (Raij e Quaggio, 1983).

O clima é do tipo Cwa, caracterizado pelo clima tropical de altitude, com inverno seco e verão quente e chuvoso. Na Figura 1 encontram-se os dados de precipitação pluvial 
diária e as temperaturas máxima e mínima diárias, coletados na Estação Meteorológica do Departamento de Ciências Ambientais. Quanto à precipitação, caracterizou-se a sua freqüência de ocorrência, utilizando a série histórica dos dez últimos anos, no período em que houve o cultivo da soja (28/02 a 03/07/00) (Figura 2).

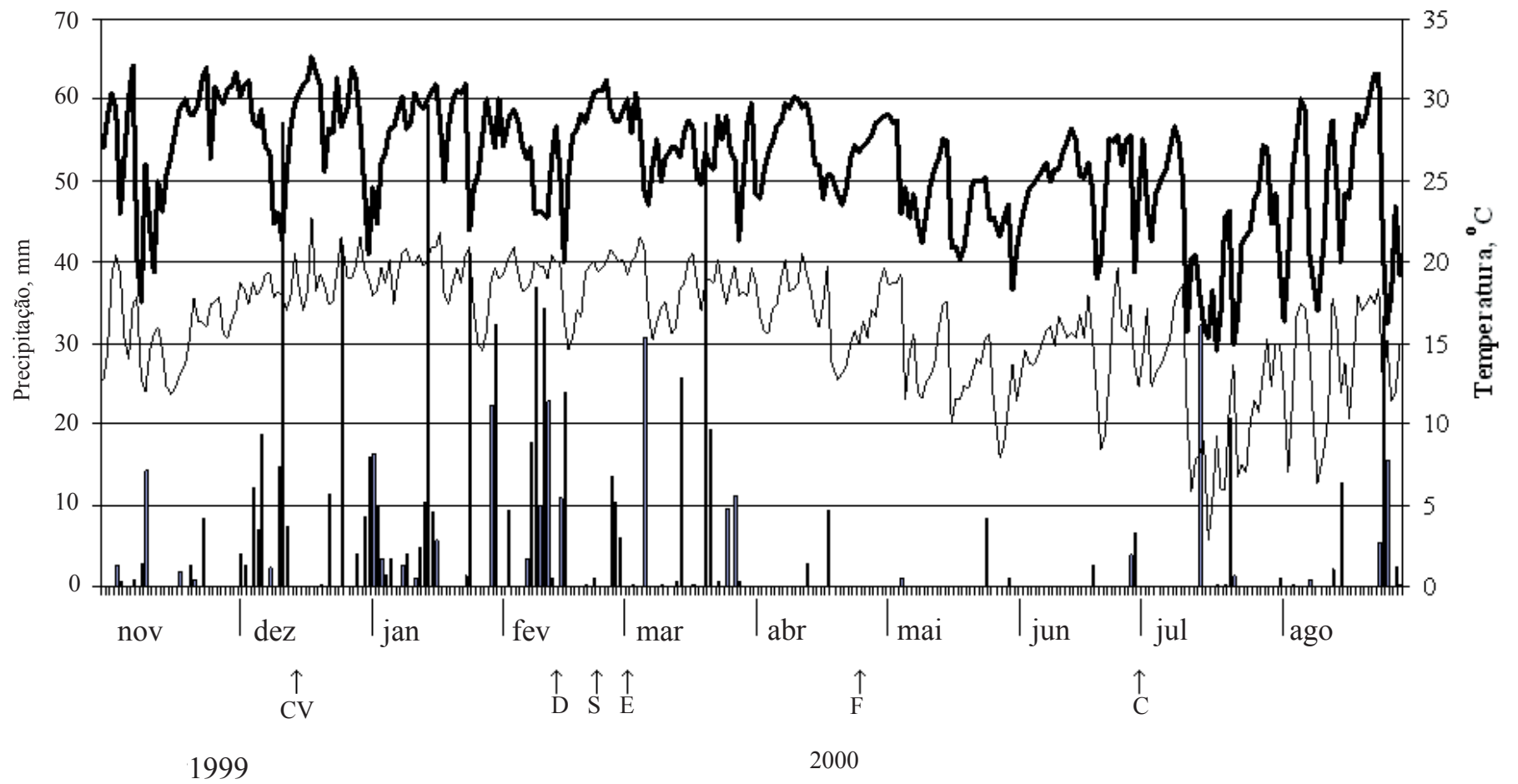

FIGURA 1. Temperaturas máximas (-) e mínimas (-), e precipitação pluvial ( | ) durante o primeiro período de condução do experimento. A condução das coberturas vegetais $(C V)$ foi iniciada em 16/12/99 e a dessecação (D) em 14/02/00; a semeadura da soja (S) foi realizada em 28/02/00, com emergência (E) em 02/03/00, florescimento (F) em 24/04/00 e colheita (C) em 03/07/00. Botucatu-SP, 1999 e 2000.

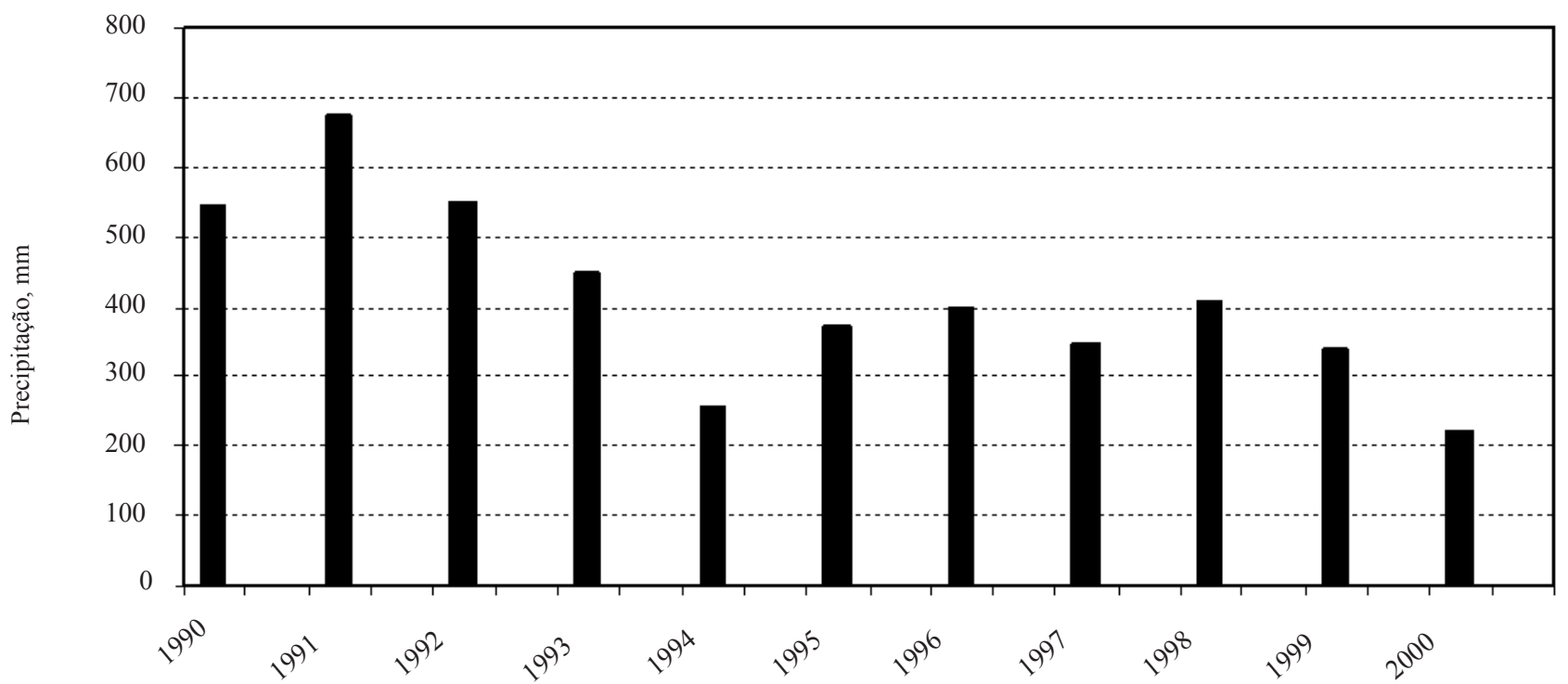

FIGURA 2. Precipitação pluvial acumulada no período de 28 de fevereiro a 3 de julho nos anos de 1990 a 2000. Botucatu-SP. 
O delineamento experimental utilizado foi o de blocos ao acaso em parcela subdividida, com quatro repetições. As parcelas, de $6 \mathrm{~m}$ de largura e $10 \mathrm{~m}$ de comprimento, foram constituídas pelos tratamentos de cobertura vegetal: 1-sorgo de Guiné (Sorghum bicolor Moench.), raça Guinea e pool vermelho, 2-sorgo de Guiné (Sorghum bicolor Moench.), raça Guinea e pool branco, 3-milheto (Pennisetum americanum) cv. $\mathrm{BN}_{2}$, 4-painço (Panicum dichotomiflorum Mix.) variedade amarelo brasileiro, 5-vegetação espontânea presente na área, e 6-sem vegetação. Esse último tratamento, desde a implantação do experimento, foi mantido sem vegetação, sendo as invasoras controladas periodicamente por meio de capinas manuais. Posteriormente, as parcelas foram divididas ao meio por carreadores de $50 \mathrm{~cm}$, no sentido do comprimento, formando-se assim duas subparcelas de $27,5 \mathrm{~m}^{2}$, onde uma permaneceu sem calagem e a outra recebeu a aplicação de calcário, visando à elevação da saturação por bases para $70 \%$.

O calcário utilizado foi o dolomítico, cujas características químicas e físicas, segundo procedimentos de Lanarv (1988), foram: umidade $(\%)=0,10 ; \mathrm{CaO}(\%)=33,60 ; \mathrm{MgO}(\%)=$ 18,00 ; retido na peneira $\mathrm{n}^{\circ} 10(>$ que $2 \mathrm{~mm})=0,00$; retido na peneira $\mathrm{n}^{\circ} 20($ até $0,84 \mathrm{~mm})=1,64$; retido na peneira $\mathrm{n}^{\circ} 50(>$ que $0,30 \mathrm{~mm})=18,62$; poder de neutralização $(\mathrm{PN})=100,00$; reatividade $=91,24$ e PRNT $=91,24$.

A área experimental, por vários anos, foi manejada de modo convencional, constando de arações e gradagens. Durante o ano de 1998 permaneceu sob pousio, voltando a ser cultivada de forma convencional no inverno de 1999 com aveia preta (Avena strigosa). Quando da instalação do experimento, a emergência de aveia preta e da vegetação original cobriam completamente o solo de toda área experimental. Essa fitomassa foi dessecada com a aplicação de $1.920 \mathrm{~g}$ i.a.ha ${ }^{-1}$ de herbicida à base de glyphosate, duas semanas antes da semeadura direta das coberturas vegetais, ocorrida em 16/12/1999.

Para a semeadura das coberturas vegetais foi utilizando a proporção de $20 \mathrm{~kg} \cdot \mathrm{ha}^{-1}$ de sementes para todas as espécies (Wutke, 1993), sendo que em função do teor de água e do espaçamento adotado foi possível determinar o número total de sementes por grama e a quantidade depositada por metro, sendo 71, 77, 98 e 91 sementes. $\mathrm{m}^{-1}$ para o sorgo vermelho e branco, milheto e painço, respectivamente. Também foi determinada a germinação das sementes utilizadas, sendo 89 , 50,78 e $74 \%$ para o sorgo vermelho e branco, milheto e painço, respectivamente. A semeadura ocorreu de forma mecanizada e direta, sobre a "palhada" da aveia preta + vegetação original, com o emprego de semeadoras-adubadoras de plantio direto, sendo uma com 6 linhas espaçadas a $60 \mathrm{~cm}$ entre si $\left(\mathrm{PST}_{2}\right.$ da
Tatu), para os sorgos, e outra de 15 linhas espaçadas a $20 \mathrm{~cm}$ (TD 300 da Semeato), para milheto e painço.

Juntamente com a semeadura foi aplicado $20 \mathrm{~kg}$. ha $^{-1}$ de $\mathrm{P}_{2} \mathrm{O}_{5}$ (Ambrosano e Wutke, 1997), em todas as parcelas, correspondendo a, aproximadamente, 50kg.ha- ${ }^{-1}$ de superfosfato triplo. $\mathrm{O}$ adubo fosfatado foi misturado, em betoneira, às sementes de milheto e painço, no dia da semeadura, em função de serem muito pequenas $(<2,0 \mathrm{~mm})$ e não disporem de semeadoras apropriadas, com regulagem precisa, para distribuição isolada de sementes e fertilizantes (Lima et al., 2001). Assim, o adubo serviu como via de transporte na proporção de $0,4 \mathrm{~g}$ de sementes para cada $1 \mathrm{~g}$ de adubo depositado por metro. No caso dos sorgos, a semeadura e a adubação fosfatada ocorreram por vias de deposição isoladas, na proporção de $1,2 \mathrm{~g}$ de sementes e $3 \mathrm{~g}$ de superfosfato triplo por metro.

A emergência ocorreu 7 dias após a semeadura (23/12/1999), para todas as coberturas. Aos 53 dias após a emergência (DAE) (14/02/2000), as coberturas vegetais foram dessecadas com a aplicação mecanizada de herbicida a base de glyphosate. Utilizou-se rolo faca uma semana após a dessecação das coberturas vegetais (21/02/2000), com o objetivo de acamar as plantas, facilitando a calagem em superfície. A calagem foi realizada em 23/02/2000, de forma manual e a lanço, na dose de 3,1 tha ${ }^{-1}$. Apesar da recomendação de V\% a ser atingida para a soja no estado de São Paulo, na camada de 0 a $20 \mathrm{~cm}$, seja $60 \%$ (Mascarenhas e Tanaka, 1997), a escolha por $70 \%$ fundamentou-se no fato de que na implantação de um sistema de rotação e sucessão, deve-se atender não mais a necessidade de uma única cultura, mas sim do sistema como um todo.

A cultivar de soja utilizada foi a IAC-19, cujo hábito de crescimento é determinado, com florescimento de 55 a 60 dias, ciclo médio de maturação (130 a 140 dias), altura de planta de 80 a $110 \mathrm{~cm}$ e peso de 100 sementes igual a $15 \mathrm{~g}$, quando semeada de outubro a dezembro (IAC, $1998 \mathrm{e}$ 1999). Nesta condição, a densidade populacional ótima varia de 300.000 a 400.000 plantas.ha ${ }^{-1}$, com rendimento provável de 2.400 a $3.000 \mathrm{~kg} \cdot \mathrm{ha}^{-1}$ (IAC, 1998 e 1999). A cv. IAC-19 é indicada para solos de média à alta fertilidade dos estados de SP, MG, GO, MS e MT (IAC, 1998 e 1999). Apesar de não haver pesquisa específica, acredita-se que a cultivar utilizada possa apresentar tolerância ao Al, em função de ser originaria do cruzamento entre IAC-8 x D-72-9601, mesmo sabendose que a cv. IAC-8 foi classificada como genótipo sensível ao Al em solução (Menosso et al., 2000). Porém, tanto a cv. IAC-8 como a linhagem D-72-9601 possuem a cv. Bragg na sua constituição genética, por meio de retrocruzamento. Assim, sabe-se que a cv. Bragg é tolerante ao $\mathrm{Al}$, em função de 
possuir a cv. Jackson como pai tolerante (Menosso et al., 2000).

Antes da semeadura, as sementes de soja foram inoculadas com estirpes selecionadas de Bradyrhizobium japonicum, por meio de inoculante turfoso. Como a área já havia sido cultivada com soja em safras passadas, utilizou-se $250 \mathrm{~g}$ de inoculante por $50 \mathrm{~kg}$ de sementes (Mascarenhas e Tanaka, 1997). A semeadura da soja foi realizada em 28/02/2000, duas semanas após a dessecação das coberturas vegetais, por meio de semeadora-adubadora de plantio direto, com seis linhas, modelo $\mathrm{PST}_{2}$, na densidade de 19 sementes. $\mathrm{m}^{-1}$, ou seja, aproximadamente 400.000 sementes.ha- ${ }^{-1}$ e espaçamento de $45 \mathrm{~cm}$ entrelinhas. A emergência ocorreu três dias após a semeadura (02/03/2000). Como o cultivo se deu no período de outono-inverno, havendo a possibilidade de diminuição da atividade simbiótica, realizou-se, além da inoculação, a aplicação de $50 \mathrm{~kg} \cdot \mathrm{ha}^{-1}$ de N, sendo aproximadamente $1 / 4$ dessa dose no sulco de semeadura e o restante em cobertura antes do florescimento (Mascarenhas e Tanaka, 1997).

A adubação mineral de semeadura utilizada foi de $40 \mathrm{~kg}$. ha $^{-1}$ de $\mathrm{P}_{2} \mathrm{O}_{5}$ e $50 \mathrm{~kg} \cdot \mathrm{ha}^{-1}$ de $\mathrm{K}_{2} \mathrm{O}$ (Mascarenhas e Tanaka, 1997). Para tal, empregou-se $150 \mathrm{~kg} \cdot \mathrm{ha}^{-1}$ da fórmula NPK 8-28-16, nas formas de uréia, superfosfato triplo e cloreto de potássio, misturando-se a esta mais $44 \mathrm{~kg}$ de $\mathrm{KCl}$. A adubação mineral de cobertura foi realizada em 28/03/2000 aplicandose $38 \mathrm{~kg} \cdot \mathrm{ha}^{-1}$ de N, correspondendo a $85 \mathrm{~kg} \cdot \mathrm{ha}^{-1}$ de uréia, sobre a superfície do solo úmido, ao longo e perto das fileiras de soja.

Determinou-se o estande final da soja por subparcela, por estimativa realizada em função da contagem do número de plantas seqüenciadas em amostras de $1 \mathrm{~m}$. Pouco antes da colheita, foram também amostradas 10 plantas em seqüência por subparcela, determinando-se a altura de inserção da primeira vagem, altura de planta, número total de vagens e vagens chochas por planta, número de sementes por vagem total e massa de 100 sementes.

No dia 3 de julho de 2000, aos 123 dias após a emergência, estando às plantas de soja no estádio R8 (maturação) (Fehr et al., 1971), as mesmas foram colhidas. A produtividade de sementes foi avaliada a partir da colheita e trilhagem mecânica das duas linhas centrais de $9 \mathrm{~m}$ em cada subparcela (já descontados $0,5 \mathrm{~m}$ de bordadura nas extremidades), realizada com colhedora própria de parcelas e trilhagem mecânica, modelo Nurserymaster da Wintersteiger. As produtividades, em kg.ha ${ }^{-1}$, foram ajustadas para 13\% de água.

As sementes obtidas em cada parcela foram acondicionadas em sacos de papel e mantidas no Laboratório de Análise de sementes da FCA/UNESP, durante a avaliação da qualidade fisiológica, por meio dos testes de: germinação: utilizando-se quatro subamostras de 50 sementes para cada parcela, semeadas em rolo de papel germitest, umedecido com volume de água equivalente a 2,5 vezes o peso do substrato e mantidas a temperatura de $25^{\circ} \mathrm{C}$, sendo a primeira contagem no dia $5^{\circ}$ dia após a semeadura e a última avaliação no $8^{\circ}$ dia (Brasil, 1992); envelhecimento artificial: conduzido com quatro subamostras de 50 sementes para cada tratamento, sendo que as sementes foram distribuídas sobre uma tela de alumínio fixada no interior de caixas de gerbox, funcionando como uma mini-câmara, onde após adição de $40 \mathrm{~mL}$ de água, as mesmas foram levadas para o germinador à temperatura de $42^{\circ} \mathrm{C}$ por $48 \mathrm{~h}$ (Marcos-Filho et al., 1987); germinação a temperatura subótima: manteve-se a temperatura baixa e constante, não excedendo $18^{\circ} \mathrm{C}$, adotando-se a mesma metodologia do teste de germinação (Brasil, 1992); massa seca de plântula: obtida com quatro subamostras de 20 sementes por tratamento e avaliação aos sete dias após (Krzyzanowski et al., 1991); e condutividade elétrica: utilizando-se três subamostras de 50 sementes para cada parcela, previamente pesadas em balança com precisão de $0,01 \mathrm{~g}$, imersas em um recipiente com $75 \mathrm{~mL}$ de água destilada e mantidas em câmara a $25^{\circ} \mathrm{C}$ durante 24 horas. Após esse período, foi feita a leitura da solução do exsudado com o auxílio de condutivímetro modelo Digimed DM 31, sendo depois calculada a condutividade em $\mu \mathrm{S} \mathrm{cm}^{-1} \cdot \mathrm{g}^{-1}$ de sementes em função do peso inicial das sementes (Aosa, 1983).

Efetuaram-se análises de variância e aplicação do teste F, comparando-se as médias pelo teste de Duncan a $5 \%$. Todos os cálculos foram realizados por meio do programa de computador ESTAT (Banzato e Kronka, 1989).

\section{RESULTADOS E DISCUSSÃO}

O ciclo da cv. IAC-19 foi de 123 dias, o que significou uma redução entre 7 a 17 dias, em relação a um cultivo realizado com semeadura entre outubro a dezembro (IAC, 1998 e 1999). Observou-se que a redução no ciclo de cultivo da soja em "safrinha" foi atribuída, principalmente, em função da diminuição no período reprodutivo, já que os números de dias para o florescimento (53 dias), pouco diferiram em relação à época de cultivo convencional (55 a 60 dias) (IAC, 1998). A provável causa para a redução no ciclo, normalmente deve-se ao fotoperíodo (Crusciol, 1992). No entanto, considerou-se a redução no ciclo da cv. IAC19 como pequena, provavelmente por ter a cv. IAC-8 como um dos parentais. Em trabalho realizado por Crusciol (1992), com diferentes cultivares de soja semeadas no período de inverno, constatou-se que a IAC-8 foi a que se mostrou menos sensível à variação do fotoperíodo, principalmente quanto ao seu ciclo, altura de inserção da primeira vagem e 
altura de planta.

$\mathrm{Na}$ Tabela 1, verifica-se que não houve interação significativa entre os dois fatores aplicados sobre as variáveis analisadas. Apesar dos efeitos não significativos observados, as coberturas vegetais no SSD, podem exercer efeitos positivos e negativos, ou mesmo mostrarem-se indiferentes, sobre o desenvolvimento de plantas de soja em seqüência.
Quanto à calagem, a pesquisa por muito tempo tem procurado estudar o efeito desta na cultura da soja, sendo a sua resposta bastante conhecida na literatura científica quando se trata de cultivo convencional (Rossetto et al., 1994), existindo dúvidas com relação à aplicação de calcário na superfície do solo em SSD (Caires et al., 1998), provavelmente em função da utilização de genótipos tolerantes ao Al.

TABELA 1. Estande final, altura de inserção da primeira vagem, altura de planta, número total de vagens e vagens chochas por planta, número de sementes por vagem total, massa de 100 sementes e produtividade da soja cultivada em "safrinha" sob semeadura direta, em função da cobertura vegetal e da calagem superficial. Botucatu-SP, 2000.

\begin{tabular}{|c|c|c|c|c|c|c|c|c|}
\hline Fatores & $\begin{array}{l}\text { Estande final } \\
\qquad(1.000 \\
\text { plantas.ha-1) }\end{array}$ & $\begin{array}{c}\text { Altura de } \\
\text { inserção da } \\
1^{\circ} \text { vagem } \\
(\mathrm{cm})\end{array}$ & $\begin{array}{c}\text { Altura } \\
\text { de planta } \\
(\mathrm{cm})\end{array}$ & $\begin{array}{l}\text { Número } \\
\text { total de } \\
\text { vagens/ } \\
\text { planta }\end{array}$ & $\begin{array}{c}\text { Número } \\
\text { de Vagens } \\
\text { chochas/ } \\
\text { planta }\end{array}$ & $\begin{array}{l}\text { Número } \\
\text { de } \\
\text { sementes } \\
\text { /vagem } \\
\text { total }\end{array}$ & $\begin{array}{l}\text { Massa de } \\
100 \\
\text { sementes } \\
(\mathrm{g})\end{array}$ & $\begin{array}{l}\text { Produtividad } \\
\text { e de } \\
\text { sementes } \\
\left(\mathrm{kg} \cdot \mathrm{ha}^{-1}\right)\end{array}$ \\
\hline \multicolumn{9}{|l|}{ Cobertura Vegetal (C.V.) } \\
\hline Sorgo de Guiné Vermelho & $260 \mathrm{ab}$ & 23 & 54 & 11,5 & 0,3 & 2,0 & 13,7 & 705 \\
\hline Sorgo de Guiné Branco & $259 a b$ & 22 & 56 & 10,8 & 0,4 & 2,0 & 13,3 & 789 \\
\hline Milheto & $263 \mathrm{a}$ & 23 & 56 & 11,1 & 0,6 & 1,9 & 13,5 & 818 \\
\hline Painço & $234 \mathrm{~b}$ & 22 & 56 & 12,4 & 0,4 & 1,9 & 13,4 & 739 \\
\hline Vegetação Espontânea & $250 \mathrm{ab}$ & 21 & 50 & 9,2 & 0,3 & 1,9 & 13,1 & 659 \\
\hline Sem Vegetação & $251 \mathrm{ab}$ & 24 & 60 & 12,7 & 0,4 & 1,9 & 13,1 & 809 \\
\hline \multicolumn{9}{|l|}{ Calagem Superficial (C.S.) } \\
\hline Sem Calcário & 247 & 23 & 55 & 11,1 & 0,4 & 1,9 & 13,3 & 761 \\
\hline Com Calcário & 212 & 22 & 55 & 11,5 & 0,4 & 1,9 & 13,4 & 746 \\
\hline \multicolumn{9}{|l|}{ Valor de F } \\
\hline C.V. & $1,63 \mathrm{~ns}$ & $0,47 \mathrm{~ns}$ & $0,76 \mathrm{~ns}$ & $0,84 \mathrm{~ns}$ & $0,86 \mathrm{~ns}$ & $1,05 \mathrm{~ns}$ & $0,68 \mathrm{~ns}$ & $0,52 \mathrm{~ns}$ \\
\hline C.S. & $1,55 \mathrm{~ns}$ & $0,54 \mathrm{~ns}$ & $0,09 \mathrm{~ns}$ & $0,13 \mathrm{~ns}$ & $0,06 \mathrm{~ns}$ & $0,01 \mathrm{~ns}$ & $0,41 \mathrm{~ns}$ & $0,23 \mathrm{~ns}$ \\
\hline C.V. x C.S. & $0,47 \mathrm{~ns}$ & $0,60 \mathrm{~ns}$ & $0,26 \mathrm{~ns}$ & $0,63 \mathrm{~ns}$ & $0,67 \mathrm{~ns}$ & $0,38 \mathrm{~ns}$ & $0,27 \mathrm{~ns}$ & $1,45 \mathrm{~ns}$ \\
\hline \multicolumn{9}{|l|}{$\overline{C V}(\%)$} \\
\hline C.V. & 9,22 & 17,49 & 20,05 & 34,77 & 11,59 & 6,27 & 5,50 & 32,88 \\
\hline C.S. & 12,04 & 11,25 & 12,89 & 31,06 & 11,71 & 9,38 & 5,75 & 14,85 \\
\hline
\end{tabular}

Médias seguidas por letras iguais e sem letras, na coluna, dentro de cada parâmetro não diferem entre si pelo teste de Duncan a $5 \%$ * e ** Significativo a 5 e $1 \%$ pelo teste $\mathrm{F}$, respectivamente, e ns - Não significativo.

O número de plantas de soja do estande final não foi influenciado significativamente pelos fatores cobertura vegetal e calagem superficial (Tabela 1). Entretanto, pelo teste de comparação de médias houve diferença estatística entre as coberturas vegetais, destacando-se o milheto responsável pelo maior estande final. Ressalta-se que mesmo neste caso, o valor alcançado (263.000 plantas.ha ${ }^{-1}$ ), não foi a densidade populacional ótima recomendada para semeadura de verão, ou seja, de 300.000 a 400.000 plantas.ha $^{-1}$ (IAC, 1999). A condição ambiental adversa do cultivo de outono-inverno
(Figura 1) foi considerada como o principal motivo para a drástica redução de todos os estandes finais, independente do tratamento, onde provavelmente a maior produção de M.S. do milheto (10 t.ha $\left.{ }^{-1}\right)$, amenizou a deficiência hídrica na fase inicial do cultivo da soja, proporcionando o estabelecimento de um maior número de plantas em relação às outras coberturas que produziram somente: 5,$6 ; 3,7 ; 2,9$ e 1,9 th.ha ${ }^{-1}$ de M.S. para o painço, vegetação espontânea, sorgo vermelho e branco, respectivamente, sobre o solo. Em trabalho realizado por Cordeiro e Souza (1999) ficou 
constatado que a utilização da vegetação espontânea não foi capaz de melhorar o estande final da soja, enquanto que a cobertura vegetal morta de milheto proporcionou resultado estatisticamente superior, devendo-se destacar que todo o ensaio foi conduzido sob irrigação por aspersão, mantendose a umidade adequada.

No que se refere à altura de inserção da primeira vagem de soja (Tabela 1), observa-se que não houve efeito significativo dos fatores testados. Delavale et al. (2000), estudando os efeitos de coberturas e manejo do calcário na implantação do SSD, verificaram que o milheto e a aveia preta, conduzidos no período de inverno-primavera sob irrigação suplementar, não influenciaram significativamente a altura de inserção da primeira vagem de soja e nem diferiram estatisticamente entre si. Neste experimento, foi constatado que o tratamento sem calcário superou significativamente os tratamentos onde o calcário foi utilizado apenas superficialmente, seja antes da semeadura das coberturas vegetais, ou antes, do manejo destas.

A altura de inserção da primeira vagem de soja é uma característica agronômica importante à operação de colheita mecânica dos grãos (Medina, 1994). Essa variável deve ser de no mínimo $13 \mathrm{~cm}$, para que se reduza as perdas durante a colheita (Queiroz et al., 1981). Assim, com relação à média dos valores absolutos da altura de inserção da primeira vagem do presente experimento, independente dos tratamentos aplicados (Tabela 1), constata-se que não houve limitações à colheita mecânica da soja cultivada em "safrinha". Cordeiro e Souza (1999), avaliando as características agronômicas da cultura da soja semeada sobre diferentes coberturas vegetais, em SSD, verificaram que o tratamento com vegetação espontânea não foi eficiente na melhoria da altura de inserção da primeira vagem de soja, que atingiu média de $7 \mathrm{~cm}$, enquanto que o milheto $\mathrm{cv}$. $\mathrm{BN}_{2}$ proporcionou resultado significativamente superior $(12 \mathrm{~cm})$. Fato interessante em relação ao trabalho anterior, foi o predomínio de espécies como tiririca, nabiça e picão-preto na vegetação espontânea, da mesma forma como o ocorrido no presente experimento.

A altura das plantas de soja não foi influenciada pelos efeitos isolados dos fatores cobertura vegetal e calagem superficial (Tabela 1). Assim, da mesma forma que o observado no presente trabalho, Barizon e Fernandes (2000) não verificaram efeitos significativos dos fatores cobertura vegetal e calagem superficial, assim como da interação, para a variável altura de planta de soja. Ao contrário, Delavale et al. (2000) constataram incremento positivo proporcionado pela cobertura vegetal de milheto. Enquanto que Cordeiro e Souza (1999), para o tratamento de vegetação espontânea, observaram que não foi eficiente na melhoria da altura de plantas de soja $(40 \mathrm{~cm})$, sendo o milheto estatisticamente superior ao proporcionar altura média de $75 \mathrm{~cm}$.

Ressalta-se que os valores médios de altura de planta, para todos os tratamentos aplicados (Tabela 1), não atingiram médias entre 80 e $110 \mathrm{~cm}$, conforme característica da cv. IAC-19 semeada de outubro a dezembro (IAC, 1999). Portanto, ficou claro que o déficit hídrico ocorrido no período de "safrinha" (Figura 1), foi um dos responsáveis pela baixa estatura da soja, assim como, o efeito de fotoperíodo. Sabese que em semeadura realizada fora da época convencional, normalmente, há formação de plantas de soja de menor porte e a altura de inserção da primeira vagem também é menor (Crusciol, 1992). Em trabalho realizado por Medina (1994), comparando-se a época de semeadura convencional com o período de "safrinha" em diferentes municípios do estado de São Paulo, observou que a altura final das plantas de soja de todas as cultivares utilizadas diminuiu com a semeadura tardia, em conseqüência do florescimento precoce.

O número total de vagens por planta de soja não foi influenciado significativamente pela cobertura vegetal e nem pelos tratamentos com e sem calagem (Tabela 1). Fato semelhante foi descrito por Barizon e Fernandes (2000), onde não se observou efeito isolado para doses de calcário superficial e nem para os tratamentos com e sem "palhada", sobre o número de vagens por planta de soja. No entanto, em função das condições ambientais diferentes à que foram submetidos os dois trabalhos, no de Barizon e Fernandes (2000), verificou-se aproximadamente o dobro de vagens por planta em relação aos valores obtidos no presente experimento. A questão é a de que boa disponibilidade hídrica, na fase de estabelecimento do cultivo e no estádio reprodutivo, o que não foi verificado para esta última condição (Figura 1), e o fotoperíodo adequado, venham a produzir mais flores e, conseqüentemente, mais vagens fixadas por planta. A variável número de vagens por planta é tida como o principal componente que controla a produção da cultura da soja, sendo que quanto mais tardia é a semeadura, menor é o número de nós formados na planta, e portanto, menor é o número de vagens por planta (Vernetti, 1983). Assim, quando se compara diferentes épocas de semeadura para a soja, verifica-se que no verão são obtidos valores superiores do número de vagens por planta aos do inverno, fato esse atribuído, principalmente, ao maior desenvolvimento das plantas encontrado no cultivo de verão (Crusciol, 1992).

As vagens fixadas de leguminosas podem ficar chochas, em função de problemas na fertilização dos óvulos dentro do ovário ou devido à falta de carboidratos essenciais para o enchimento dos grãos, refletindo em menores produtividades. No entanto, dos componentes da produção, redução maior 
observou-se pelos baixos números totais de vagens (Tabela 1), cuja média geral foi de 11,3 , sendo que $3,5 \%$ desse valor correspondeu a vagens chochas. Verificou-se, também, que o número de vagens chochas não foi influenciado pelos tratamentos aplicados (Tabela 1).

Para o número de sementes por vagem (Tabela 1), não houve resposta significativa aos fatores aplicados e nem ocorreram diferenças estatísticas entre os tratamentos empregados. Igualmente, Barizon e Fernandes (2000) não constataram efeito isolado e significativo de calcário superficial e de cobertura vegetal, sendo que os valores absolutos encontrados estão muito próximos dos obtidos no presente trabalho. Nakagawa et al. (1983) não encontraram diferenças significativas para o número de sementes por vagem, em função de diferentes épocas de semeadura de soja no município de Botucatu-SP.

Quanto à massa de 100 sementes, não houve efeito significativo para os fatores aplicados e nem diferença estatística entre tratamentos (Tabela 1). Barizon e Fernandes (2000), também não observaram efeito dos tratamentos sobre a massa de 100 sementes. Em contrapartida, Rosseto et al. (1994), ao estudarem o efeito do calcário aplicado convencionalmente na produção e qualidade fisiológica das sementes de soja, verificaram que esta prática propiciou maior produção de grãos e de sementes, favorecendo a uniformização da produção de sementes de maior tamanho e massa, mas que no entanto apresentaram menor qualidade física e fisiológica.

Ressalta-se o fato de que os valores de massa de 100 sementesobtidosnopresentetrabalhoforambastantepróximos ao padrão da cv. IAC-19 que é de 15g (IAC, 1998 e 1999). Portanto, independente de resposta ou não dos tratamentos aplicados sobre a cultura da soja, a massa de 100 sementes é, dos componentes da produção, aquele que apresenta a menor variação percentual em função das alterações ambientais no meio. Assim, em condições adversas como restrição hídrica, a planta preferencialmente formará poucas sementes nas vagens fixadas, ao invés de várias e mal formadas, pois seu objetivo biológico principal é a perpetuação da espécie. Portanto, o estresse hídrico ocorrido durante o período de enchimento das vagens, provavelmente, não proporcionou diminuição substancial na produção de soja devido à redução na massa de sementes (Medina, 1994). Para Nakagawa et al. (1983), a redução na produção de soja devido ao atraso na época de semeadura está mais associada ao menor número de sementes produzidas do que ao decréscimo no tamanho e, conseqüentemente, na massa de sementes.

Os resultados obtidos para a produtividade de sementes não foram significativamente influenciados pelos tratamentos
(Tabela 1). Ao contrário, Cordeiro e Souza (1999), utilizando a mesma cultivar de milheto $\left(\mathrm{BN}_{2}\right)$, constataram influência positiva da fitomassa morta desse material na produtividade de grãos de soja. Também, puderam perceber que a produção de $2.850 \mathrm{~kg} \cdot \mathrm{ha}^{-1}$ sobre a "palhada" de milheto diferiu estatisticamente da produção de $1.160 \mathrm{~kg} \cdot \mathrm{ha}^{-1}$ obtida no tratamento com vegetação espontânea, sendo que neste, as principais espécies de ocorrência foram as mesmas caracterizadas no presente trabalho. Delavale et al. (2000), em SSD recém instalado, constataram que o milheto, conduzido durante o período de inverno-primavera, sob irrigação suplementar e manejado no estádio de florescimento, incrementou positivamente a produtividade da soja.

Da mesma forma que não houve efeito significativo para a produtividade de soja em função da calagem superficial (Tabela 1), Caires et al. (2000b), também obtiveram a mesma constatação em SSD recém implantado. Delavale et al. (2000), no ano de implantação da semeadura direta, notaram que não houve diferença significativa entre os diferentes manejos de calcário utilizados, para a produtividade. Em SSD estabilizados, resultados deste tipo são bastante conhecidos e tem sido observado com certa freqüência. Caires et al. (1998, 1999 e 2000a), em todos os cultivos de soja verificaram ausência de resposta, em termos de produtividade, ao calcário aplicado na superfície. A menor resposta das culturas à calagem, no SSD, pode estar relacionada com o menor efeito tóxico do $\mathrm{Al}$, decorrente da formação de complexos orgânicos solúveis presentes nos restos vegetais, conforme mecanismo proposto por Miyazawa et al. (1996). Outra hipótese seria a dos teores de $\mathrm{Ca}, \mathrm{Mg}$ e $\mathrm{K}$ apresentarem disponibilidade suficiente no perfil do solo para manter uma relação adequada com o Al (Caires et al., 1998). Em outros trabalhos, são observadas respostas positivas da soja à aplicação de calcário na superfície em SSD, mas considerando a produção acumulada de vários anos (Oliveira e Pavan, 1996; Sá, 1999).

A produtividade média obtida no experimento foi de, aproximadamente, $753 \mathrm{~kg} \cdot \mathrm{ha}^{-1}$, não conseguindo atingir uma produtividade desejada de 2,5 a 2,9 t.ha ${ }^{-1}$ em função da adubação realizada, segundo recomendação de Mascarenhas e Tanaka (1997), caso o cultivo tivesse sido conduzido no verão. Entretanto, a produtividade esperada não é função apenas das doses aplicadas de fertilizantes, dependendo de diversos outros fatores, tal como a disponibilidade de água (Raij et al., 1997). Provavelmente a deficiência hídrica verificada durante o cultivo da soja (Figura 1), com precipitação de apenas $221 \mathrm{~mm}$ de chuvas, provocou a redução na taxa de crescimento vegetativo, expressa pela menor altura de inserção da primeira vagem e de altura de planta, diminuindo o número total de vagens e, conseqüentemente a 
produtividade (Tabela 1). Também, o efeito do fotoperíodo contribuiu consideravelmente para proporcionar menor ciclo, porte e produtividade da soja "safrinha".

Acredita-se na possibilidade de serem atingidos valores mais altos de produtividade, mesmo sem irrigação suplementar, pois pelo histórico de precipitação pluvial (Figura 2), verifica-se que o período em questão foi o de menor volume de chuvas acumuladas nos últimos dez anos, caracterizando uma forte estiagem. Essa condição hídrica adversa, também diminui a disponibilidade e a absorção dos elementos minerais, juntamente com a redução da atividade fotossintética. Isso tudo se reflete na baixa produtividade biológica, representada pela inexpressiva produção de M.S. da parte aérea da soja (média de 2,25 t.ha ${ }^{-1}$ ) no florescimento, ou seja, no estádio R6 na escala de Fehr et al. (1971), considerada baixa quando comparada aos dados apresentados por Tanaka et al. (1993), que observaram, em cultivo de verão, na média de cinco cultivares, 18,8 tha ${ }^{-1}$, havendo a conseqüente redução da produtividade de sementes no presente trabalho, independente dos tratamentos aplicados (Tabela 1).
NaTabela2, constata-seausênciadeinteraçãosignificativa entre os fatores estudados em relação à germinação e ao vigor (envelhecimento artificial, germinação a temperatura subótima, M.S. de plântula e condutividade elétrica) das sementes de soja. Também não foram constatados efeitos do fator isolado calagem na qualidade fisiológica das sementes de soja. Em contrapartida, Rossetto et al. (1993), estudando o efeito do calcário na qualidade fisiológica de sementes de soja (germinação e condutividade elétrica), também no município de Botucatu-SP, verificaram que a calagem favoreceu a produção de sementes de maior tamanho, o que representou menor qualidade fisiológica, quanto maior era a dose do corretivo, sendo que com o maior tempo de armazenamento das sementes o problema foi agravado. Portanto, ainda hoje a pesquisa em tecnologia de sementes tem procurado estudar e entender os efeitos do calcário na produção e qualidade de sementes, ainda mais quando se trata de um SSD recém implantado, sob uma condição não convencional como o cultivo em "safrinha".

TABELA 2. Valores médios de germinação, envelhecimento artificial, germinação a temperatura subótima, matéria seca de plântula e condutividade elétrica de semente de soja cultivada em "safrinha" sob semeadura direta, em função da cobertura vegetal e da calagem superficial. Botucatu-SP, 2000.

\begin{tabular}{|c|c|c|c|c|c|}
\hline Fatores & $\begin{array}{c}\text { Germinação } \\
(\%)\end{array}$ & $\begin{array}{c}\text { Envelhecimento } \\
\text { Artificial } \\
(\%)\end{array}$ & $\begin{array}{l}\text { Germinação } \\
\text { a temperatura } \\
\text { subótima }(\%)\end{array}$ & $\begin{array}{l}\text { Matéria seca } \\
\text { de plântula } \\
\left(\mathrm{mg} \cdot \mathrm{pl}^{-1}\right)\end{array}$ & $\begin{array}{c}\text { Condutividade } \\
\text { elétrica } \\
\left(\mu \mathrm{cm}^{-1} \cdot \mathrm{g}^{-1}\right)\end{array}$ \\
\hline \multicolumn{6}{|l|}{ Cobertura Vegetal (C.V.) } \\
\hline Sorgo de Guiné Vermelho & 88,0 & 77,8 & 98,3 & 0,010 & $123,78 \mathrm{ab}$ \\
\hline Sorgo de Guiné Branco & 84,7 & 76,0 & 97,3 & 0,010 & $124,23 \mathrm{ab}$ \\
\hline Milheto & 78,0 & 75,7 & 97,0 & 0,011 & $116,49 \mathrm{~b}$ \\
\hline Painço & 85,2 & 69,8 & 98,0 & 0,010 & $113,06 \mathrm{~b}$ \\
\hline Vegetação Espontânea & 80,3 & 72,7 & 96,5 & 0,011 & $120,02 \mathrm{~b}$ \\
\hline Sem Vegetação & 83,8 & 75,8 & 99,3 & 0,011 & $148,56 \mathrm{a}$ \\
\hline \multicolumn{6}{|l|}{ Calagem Superficial (C.S.) } \\
\hline Sem Calcário & 82,7 & 73,8 & 97,4 & 0,010 & 126,70 \\
\hline Com Calcário & 84,0 & 75,4 & 98,0 & 0,011 & 122,01 \\
\hline \multicolumn{6}{|l|}{ Valor de F } \\
\hline C.V. & $0,84 \mathrm{~ns}$ & $2,08 \mathrm{~ns}$ & $7,08 \mathrm{~ns}$ & $0,42 \mathrm{~ns}$ & $5,02 *$ \\
\hline C.S. & $0,26 \mathrm{~ns}$ & $0,50 \mathrm{~ns}$ & $1,78 \mathrm{~ns}$ & $2,53 \mathrm{~ns}$ & $2,23 \mathrm{~ns}$ \\
\hline C.V. x C.S. & $2,14 \mathrm{~ns}$ & $0,62 \mathrm{~ns}$ & $2,06 \mathrm{~ns}$ & $0,92 \mathrm{~ns}$ & $2,18 \mathrm{~ns}$ \\
\hline \multicolumn{6}{|l|}{$\mathrm{CV}(\%)$} \\
\hline C.V. & 11,56 & 6,56 & 0,96 & 18,42 & 11,08 \\
\hline C.S. & 9,41 & 5,11 & 1,41 & 21,55 & 7,58 \\
\hline
\end{tabular}

Médias seguidas por letras iguais e sem letras, na coluna, dentro de cada parâmetro não diferem entre si pelo teste de Duncan a $5 \%$. ${ }^{*}$ * Significativo a 5 e $1 \%$ pelo teste $\mathrm{F}$, respectivamente, e ns - Não significativo. 
Já as coberturas vegetais proporcionaram diferenças significativas para o teste de condutividade elétrica (Tabela 2). Em função desta variável, observa-se que as coberturas vegetais tenderam a influenciar positivamente o vigor das sementes de soja, pois o pior resultado foi obtido pelo tratamento sem vegetação, enquanto que o milheto e o painço, por exemplo, possibilitaram melhores resultados. Em trabalho realizado por Nakagawa et al. (2006), em Botucatu-SP, estudando a qualidade fisiológica de sementes de soja cultivada em rotação com milheto, obtiveram a melhor qualidade de sementes de soja quando a mesma foi cultivada após o cultivo do milheto. Praticamente não há estudos avaliando o efeito de sistemas de rotação e ou sucessão de culturas sobre a qualidade fisiológica de sementes, principalmente, quando cultivada em SSD, devendo novas pesquisas serem realizadas (Nakagawa et al. 2006).

\section{CONCLUSÕES}

As características agronômicas, os componentes da produção e a qualidade fisiológica das sementes de soja cultivada em "safrinha" não foram influenciados pela ação conjunta da cobertura vegetal e calagem superficial, assim como pela ação isolada da calagem, num SSD recém implantado;

Num SSD recém implantado as coberturas vegetais tenderam a influenciar positivamente apenas o vigor das sementes de soja cultivadas em "safrinha".

\section{REFERÊNCIAS}

ASSOCIATION OF OFFICIAL SEED ANALYSIS. Seed vigour testing handbook. East Lansing, 1983. 88p.

AMBROSANO, E.J.; WUTKE, E.B. Leguminosas adubos verdes: crotalária, chícharo ou ervilhaca, feijão-de-porco, feijão-guandu, lablabe, mucuna, tremoço. Boletim Técnico do Instituto Agronônico de Campinas, n.100, p.200, 1997.

BANZATO, D.A.; KRONKA, S.N. Experimentação agrícola. Jaboticabal: FUNEP, 1989. 247p.

BARIZON, R.R.M., FERNANDES, D.M. Nutrição e produção da soja, em sistema de plantio direto, em função de calagem superficial e palhada de brizantão (Brachiaria brizantha). In: FERTBIO, 2000, Santa Maria. Anais... Santa Maria: Universidade Federal de Santa Maria, 2000. 1 CDROM.

BRASIL. Ministério da Agricultura e Reforma Agrária. Regras para análise de sementes. Brasília, DF:
Departamento Nacional de Produção Vegetal, Divisão de Sementes e Mudas, 1992. 365p.

CAIRES, E.F; CHUEIRI, W.A.; MADRUGA, E.F.; FIGUEIREDO, A. Alterações de características químicas do solo e resposta da soja ao calcário e gesso aplicados na superfície em sistema de cultivo sem preparo do solo. Revista Brasileira de Ciência do Solo, v.22, p.27-34, 1998.

CAIRES, E.F; FONSECA, A.F.; MENDES, J.; CHUEIRI, W.A.; MADRUGA, E.F. Produção de milho, trigo e soja em função das alterações das características químicas do solo pela aplicação de calcário e gesso na superfície, em sistema de plantio direto. Revista Brasileira de Ciência do Solo, v.23, p.315-27, 1999.

CAIRES, E.F. Manejo da fertilidade do solo no sistema plantio direto: experiências no estado do Paraná. In: FERTBIO, 2000, Santa Maria. Anais... Santa Maria: Universidade Federal de Santa Maria, 2000. 1 CD-ROM.

CAIRES, E.F.; BANZATTO, D.A.; FONSECA, A.F. Calagem na superfície em sistema plantio direto. Revista Brasileira de Ciência do Solo, v.24, p.161-9, 2000a.

CAIRES, E.F.; BLUM, J.; FELDHAUS, I.C. Resposta da soja ao calcário e gesso aplicados na implantação do sistema plantio direto. In: FERTBIO, 2000, Santa Maria. Anais... Santa Maria: Universidade Federal de Santa Maria, 2000 b. 1 CD-ROM.

CORDEIRO, L.A.M.; SOUZA, C.M. Características agronômicas da cultura da soja (cv. 'CAC-1') semeada sobre palhada de diferentes espécies de cobertura morta em sistema plantio direto. In: CONGRESSO BRASILEIRO DE CIÊCIA DO SOLO, 27, 1999, Brasília. Anais... Brasília, DF: EMBRAPA- Centro de Pesquisa Agropecuária dos Cerrados, 1999. 1 CD-ROM.

CRUSCIOL, C.A.C. Avaliação dos caracteres produtivos, produção e qualidade fisiológica de sementes de soja, semeada no período de inverno e de verão, na região de Selvíria (MS). 1992. 46f. Relatório final apresentado a Faculdade de Engenharia de Ilha Solteira, Universidade Estadual Paulista, para conclusão de Bolsa de Iniciação Científica/PIBIC-CNPq, Ilha Solteira.

DELAVALE, F.G.; LAZARINI, E.; BUZETTI, S. Efeitos de coberturas e manejo do calcário na implantação do sistema de plantio direto em solo característico de cerrado. In: FERTIBIO, 2000, Santa Maria. Anais... Santa Maria: Universidade Federal de Santa Maria, 2000. 1 CD-ROM.

EMBRAPA. Centro Nacional de Pesquisa de Solos. Sistema brasileiro de classificação de solos. 2.ed. Brasília, 2006. 306p. 
FEHR, W.R.; CAVINES, C.E.; BURMOOD, D.T.; PENNINGTON, J.S. Stage of development descriptions for soybeans, Glycine $\max ($ L.) Merrill. Crop Science, v.11, p.929-31, 1971.

INSTITUTO AGRONÔMICO DE CAMPINAS. Novos cultivares de soja do IAC. Campinas, 1998. 1 folder

INSTITUTO AGRONÔMICO DE CAMPINAS. Melhoramento genético de soja. Campinas, 1999. 1 folder

KRZYZANOWSKI, F.C.; FRANÇA-NETO, J.B.; HENINNG, A.A.; COSTA, N.P. Relato dos testes de vigor disponíveis para as grandes culturas. Informativo ABRATES, v.1, n.2, p.15-59, 1991.

LANARV. Laboratório Nacional de Referência Vegetal. Análise de corretivos, fertilizantes e inoculantes: métodos oficiais. Brasília, DF, 1988. 104p.

LIMA, E. do V.; CAVARIANI, C.; LIMA, P.L.; CRUSCIOL, C.A.C.; NAKAGAWA, J.; VILLAS BOAS, R.L. Qualidade fisiológica de sementes de painço (Panicum dichotomiflorum Mix.) em função do tempo de mistura com o superfosfato triplo. Cultura Agronômica, v.9, p.177-189, 2001.

MARCOS-FILHO, J.; CÍCERO, S.M.; SILVA, N.R. Avaliação da qualidade das sementes. Piracicaba: FEALQ, 1987. 230p.

MASCARENHAS, H.A.A., TANAKA, R.T. Leguminosas e oleaginosas: soja. Boletim Técnico do Instituto Agronômico de Campinas, n.100, p.202-3, 1997.

MEDINA, P.F. Produção de sementes de cultivares precoces de soja, em diferentes épocas e locais do Estado de São Paulo. 1994. 173f. Tese (Doutorado em Agronomia/ Fitotecnia) - Escola Superior de Agricultura "Luiz de Queiroz", Universidade de São Paulo, Piracicaba.

MENOSSO, O.G.; COSTA, J.A.; ANGHINONI, I.; BOHNEN, H. Tolerância de genótipos de soja ao alumínio em solução. Pesquisa Agropecuária Brasileira, v.35, p.375-83, 2000.

MIYAZAWA, M.; PAVAN, M.A.; SANTOS, J.C.F. Effects of addition of crop residues on the leaching of $\mathrm{Ca}$ and $\mathrm{Mg}$ in Oxisols. In: INTERNATIONAL SYMPOSIUM ON PLANT-SOIL INTERACTIONS AT LOW pH, 4, 1996, Belo Horizonte. Abstracts... Belo Horizonte: Sociedade Brasileira de Ciência do Solo, EMBRAPA-CPAC, 1996. p.8.

NAKAGAWA, J.; ROSOLEM, C.A.; MACHADO, J.R. Épocas de semeadura da soja. I. Efeitos na produção. Pesquisa Agropecuária Brasileira, v.18, p.1187-98, 1983.

NAKAGAWA，J.; LEMOS， L.B.; CAVARIANI， C.;
PENARIOL, F.G. Qualidade fisiológica de sementes de soja cultivada em rotação com milheto. Revista Brasileira de Sementes, v.28, n.1, p.36-44, 2006.

OLIVEIRA, E.L.; PAVAN, M.A. Control of soil acidity in no-tillage system for soybean production. Soil \&TillageResearch, v.38, p.47-57, 1996.

QUEIROZ, E.F.; NEUMAIER, N.; TORRES, E.; PEREIRA, L.A.G.; BIANCHETTI, A.; TERAZAWA, F.; PALHANO, J.B.; YAMASHITA, J. Recomendações técnicas para a colheita mecânica. In: MIYASAKA, S., MEDINA, J.C. (Ed.). A soja no Brasil. Campinas: ITAL, 1981. p.701-10.

RAIJ, B.; CANTARELLA, H.; QUAGGIO, J.A.; FURLANI, A.M.C. Recomendações de adubação e calagem para o estado de São Paulo. Boletim Técnico do Instituo Agronônico de Campinas, n.100, 1997. 285p.

RAIJ, B.; QUAGGIO, A.J. Métodos de análise de solo para fins de fertilidade. Boletim Técnico do Instituo Agronômico de Campinas, n.81, 1983. 31p.

RASSINI, J.B.; LIN, S.S. Efeito de períodos de estiagens artificiais durante estádios de desenvolvimento da planta no rendimento e qualidade da semente de soja (Glycine Max (L.) Merrill). Agronomia Sulriograndense, v.17, p.225-37, 1981.

ROSSETO, C.A.V.; FERNANDEZ, E.M.; NAKAGAWA, J.; ROSOLEM, C.A. Efeito do calcário na produtividade e qualidade fisiológica das sementes de soja (Glycine Max (L.) Merrill). Revista Brasileira de Sementes, v.16, p.208-15, 1994.

SÁ, J.C.M. Manejo da fertilidade do solo no sistema plantio direto. In: SIQUEIRA, J.O.; MOREIRA, F.M.S.; LOPES, A.S.; GUILHERME, L.R.G.; FAQUIN, V.; FURTINI NETO, A.E.; CARVALHO, J.G. (Ed.). Inter-relação fertilidade, biologia do solo e nutrição de plantas. Viçosa: SBCS, Lavras: UFLA/DCS, 1999. p.267-319.

TANAKA, R.T.; MASCARENHAS, H.A.A.; BORKERT, C.M. Nutrição mineral da soja. In: ARANTES, N.E.; SOUZA, P.I.M. (Ed.). Cultura da soja nos cerrados. Piracicaba: Potafos, 1993. p.105-35.

VERNETTI, F.J. Genética da soja: caracteres qualitativos. In: VERNETTI, F.J. (Ed.). Soja: genética e melhoramento. Campinas: Fundação Cargill, 1983. p.93-124.

WUTKE, E.B. Adubação verde: manejo da fitomassa e espécies utilizadas no estado de São Paulo. In: WUTKE, E.B.; BULISANI, E.A.; MASCARENHAS, H.A.A. (Coord.). Curso sobre adubação verde no Instituto Agronômico. Campinas: Instituto Agronômico, 1993. p.17-29. (IAC. Documento, 35). 